The reconceptualization of genetically heterogeneous elements in functional categories also influenced the character of linguistic consciousness. The bookish language was perceived not as an alien tongue that existed independently of the native language (in contrast to Latin) but as a cultivated variety of it. The mastery of the bookish language was superimposed onto native linguistic ways and united with them, forming the complex conglomerate of the speech habits of the written language whose concrete content depended both on the social and cultural status of the writer as well as on the type of written texts that he usually produced (these are understandably connected). Differing writing habits that primarily come from reading create different written traditions that have dissimilar cultural (and religious) importance. Linguistic phenomena that are characteristic of each of the written traditions (registers) acquire the same cultural weight as the tradition as a whole, and this significantly defines their role in the creation of the new type of literary language.

\title{
3. The Main Registers of the Bookish Language and the Processes of Their Formation
}

The main division in the written language of medieval Rus' was into bookish and non-bookish texts. Bookish texts were characterized primarily by their logically ordered and rhetorically organized syntax and their use of markers of bookishness (for example, forms of the imperfect or gerunds in agreement with their subjects). The syntax of non-bookish texts was oriented on the communicative situation (on what the addressee knows or doesn't know), so that the pragmatic structure plays a significantly greater role than logical organization, and markers of bookishness are not used (except for isolated cases and clichéd formulas). However, the division into bookish and non-bookish languages alone is not sufficient for describing the linguistic situation of medieval Rus' insofar as the linguistic features of both kinds of text are too heterogeneous to see them as opposing unities. This is one of the issues that prevents us from defining the linguistic situation of the Eastern Slavs as diglossia, as it does, for example, the coexistence of classical Arabic and modern Arabic languages. ${ }^{4}$

However, it seems that in the case of Arabic as well the division into "high" and "low" languages is not as unambiguous as one might conclude from classical descriptions of Arabic diglossia (see Ferguson 1959). Here too there are texts that significantly diverge from the bookish standard (Talmoudi 1984), but it is not clear if they form a discrete tradition. 
Within the framework of the bookish language at least two registers stand out, one of which may be called standard and the other hybrid. The standard register is realized primarily in texts of the main corpus, i.e., Holy Writ and liturgy; from among these the texts that were learned by heart had the greatest impact. A significant part of the standard bookish texts were nonEastern Slavic in origin, including texts of the main corpus, on which the entire given written tradition was directly based. Texts from other Slavic traditions were adapted on Eastern Slavic soil on the orthographic and morphological levels, but their syntactic construction and grammatical structure did not experience any major influence of the non-bookish language of the Eastern Slavs. Those original Eastern Slavic works that were created primarily via the mechanism of orientation on texts also belong to this register. The clearest illustration of this is the already mentioned Eastern Slavic additions to the service menalogia whose language does not differ from that of the basic text that came from the South Slavs.

The hybrid register was realized in original Eastern Slavic texts (that is, texts created by Eastern Slavic bookmen; naturally, these could also be translations from Greek, Latin or some other language). If works in the standard register were created primarily by the mechanism of orientation on texts, the main role in creating texts in the hybrid register was played by the mechanism of retabulation. The mechanism of retabulation created the possibility of the writer's special linguistic stance in which the goal was not the maximal convergence of the language of the new texts with that of the corpus of basic texts but the relative similarity of these languages according to a series of formal markers. Understandably, given this stance the set of relevant formal markers only has relative significance and may be reduced to a minimum, including primarily those features that most clearly differentiate the bookish language from the non-bookish. The choice of markers that are involved with the retabulation is limited and selective. Together with this, the use of the formal markers that belong to the set is also selective; insofar as these markers primarily function as indicators of the bookish nature of the text, they may be used inconsistently and infrequently, as their very presence serves as the indicator, while the degree of their use depends on various particular factors.

Insofar as the use of markers of bookishness in such texts takes on the character of a signal, extensive influence of the non-bookish language on the bookish becomes possible. The identification of especially bookish elements in linguistic consciousness acquires a completely functional character as the process of functional reconceptualization of genetic heterogeneity is brought to its logical limit. Without the direct orientation on the texts of 
the basic corpus and grammatical codification variability increases greatly and elements of non-bookish origin freely make their way into new texts. Thus in this register of the bookish language bookish and non-bookish elements are synthesized into a single system, so that the very question of the linguistic basis of the corresponding texts as traditionally bookish or as popular and conversational (that has been debated many times without any notable results - cf. Vinogradov 1958; Vinogradov 1978, 65-151) turns out to be without any basis. Either of these two aspects may be seen in isolation but the functioning of this type of text can only be understood in terms of their combination and interaction. It is for this very reason that we find it appropriate to label this register of the bookish language hybrid.

In the context of the hybrid register usage fundamentally depends on the correlation of the bookish and non-bookish languages, insofar as the markers of bookishness are what distinguish them in the linguistic consciousness of users. Due to the fact that the standard of the bookish language was based on model Church Slavonic texts and remained largely unchanged over the course of centuries, the set of the markers of bookishness and changes in this set were conditioned by features of the non-bookish language. Thus in the Russian tradition as represented by texts of the fifteenth through seventeenth century, the markers of bookishness include: simple preterits, active participles and, in general, participles as gerunds in agreement with their subjects, forms of the dual number, the dative absolute, etc. Changes in the non-bookish language influenced the make-up of the hybrid register. The dual number, for example, acquired the status of a marker of bookishness, naturally, only after it disappeared from the non-bookish language. ${ }^{5}$

However, this fundamental dependence only determined the basic contours, not the details. The details were worked out with reference to the

\footnotetext{
The hybrid register, as a natural consequence of the functioning of the mechanism of retabulation, was characteristic not only of the written language of the Eastern Slavs but also of the Southern Slavs (analogous phenomena may also certainly be seen in other language groups, but this is another topic). The set of markers of bookishness, however, is specific in each case, and it is precisely these specifics that clearly display the dependence of what constitutes the hybrid register on the special features of the non-bookish language. Naturally, Bulgarians did not perceive the forms of the simple preterits as specific to the bookish language, so they did not become markers of bookishness in the framework of the Bulgarian tradition. For the Bulgarian tradition markers of bookishness included: noun and adjective case forms, the absence of articles, infinitives in - $m u$, the simple future, synthetic forms of the comparative degree, etc. This set of markers came into being by virtue of the fact that they became alien to living Bulgarian idioms. As one can see, similar mechanisms of producing bookish texts in differing Slavic traditions give significantly different results, which is ultimately attributable to the differences among the living languages.
} 
continuity of usage, and the fact that in creating a hybrid text a bookman directly turns not to his conversational tongue but to the sum total of his linguistic experience in which reading (i.e., the assimilation of written texts) plays no less a role than spontaneous speech. Slavic scholars ignored hybrid languages for a long time precisely because all of their attention was focused on the correlation between the bookish and spoken language, while they only ascribed an organic systematic character to the latter. The absolutized dichotomy of nature and culture that became a basic myth of the Neogrammmarians and that has survived as an article of faith practically until the present day thanks to structuralism and structuralist semiotics led to the rejection of any "natural" aspects of written language which was seen as a cultural phenomenon par excellence. This dichotomy also defined the history of Church Slavonic, on the one hand as a completely artificial language (with emphasis given to the standard register), and on the other as contrasted to the completely natural living language. Between these two poles was chaos that scholars simply did not wish to deal with, as hybrid texts were seen as conglomerations of heterogeneous material. However, if we ascribe to written usage the same natural continuity that oral usage has (realized in the transfer of reading habits into habits of writing), then the hybrid register appears (in the words of R. Mathiesen) not as "a mere conglomerate of heterogeneous elements, but [as] a secondary linguistic system in its own right" (Mathiesen 1984, 47). ${ }^{6}$

The continuity of writing habits explains how the relatively stable and relatively autonomous use of the hybrid register developed. It was not only the selection of relevant markers of bookishness and the consideration of differences between the standard bookish and non-bookish languages that were the individual decision of each author but the way in which particular elements were used that gave continuity to the language of successive generations of bookmen, a language which underwent changes that were gradual and "organic" (even from the point of view of the nature-culture dichotomy that we have rejected). Analysis of the heterogeneous language of hybrid texts (primarily chronicles) shows that the sections bookmen reproduced based on chronologically distant sources and those which they wrote themselves are connected by an uninterrupted chain of links that demonstrates the gradual nature of the evolution of usage (cf. Zhivov 1995a; Petrukhin 1996).

Furthermore, in my opinion the epithet "secondary" is completely superfluous here and is a concession to the reigning line of linguistic thought that leads from the Neogrammarians to the Structuralists, for which writing is always secondary, artificial, and therefore requiring the exclusion of phenomena connected with it from properly linguistic investigation (cf. Derrida 1967; Derrida 1968). 
This evolution proceeded thanks to constant semantic reinterpretation. Because the assimilation of the earlier bookish tradition took place without the aid of grammars and dictionaries, reading presupposed the interpretation of the linguistic material in those semantic categories which were within the reach of the author (first of all from linguistic experience connected to colloquial usage). Trying to preserve the formal elements that were characteristic of the existing written corpus, the author did this to the extent that he could, making use of these elements as he understood them in the context of the material that he had assimilated. Understandably, this usage could significantly differ from the original structure of the assimilated texts. The degree of difference evidently depended on two things: in the first place, the extent to which the language of these texts differed from the spoken language of the author (in terms of some concrete feature), and in the second place, the author's individual situation, that is, his education, his feel for language, and his desire to reproduce the language of his predecessors (either in a general way or in all things). The manner of transmission of linguistic habits from generation to generation does not differ here in its structure from that observed in the oral (living) language and functions as the standard of "naturalness" for the study of language oriented on "nature."

The evolution of the use of the perfect in the Laurentian Chronicle, brilliantly analyzed in the recent work of E. Klenin (1993), may serve as a good illustration of this. According to her observations, the perfect and aorist gradually redistribute their functions. Initially the perfect is used in the resultative meaning (which may refer both to the present and the past) and the aorist is used as the basic narrative tense. In the oldest part of the chronicle (the "Primary Chronicle" [Povest' vremennykh let]), there are already rare examples (precisely, two) where the perfect is used in narrative fragments, although in both cases not for presenting successive actions but for designating isolated events. In the section from the twelfth century this last usage becomes more widespread, and the perfect is used in fragments of commentary when indicating isolated actions or when there are gaps in narrative continuity. Isolated examples of the perfect in describing continuous action only occur in the last part of the chronicle ( $\Omega$-forms alternate with the aorist that is more usual in the given context).

Insofar as this evolution seems "natural," Klenin interprets this data as evidence of changes in the living language in which the functions of the perfect are expanding, gradually displacing use of the aorist, one function at a time. This interpretation corresponds to traditional views that "naturalness" and a systematic quality exclusively belong to the living language, while any changes in the bookish language, if they are not merely completely 
artificial, are of a "secondary" character. One may conclude with equal success that the expansion of the perfect's sphere of use takes place due to reinterpretation, when each successive chronicler builds upon the precedents left to him by his predecessor, assigning them more general significance; the resultative is perceived to be any non-narrative usage, non-narrative usage is then understood as a category applicable to any action mentioned outside of strict narrative order, and so on. The stimulus to such an interpretation indeed apparently comes from the conversational language, in which the use of the perfect differs (say, in the fourteenth century) from that which the later chronicler finds in his earlier sources, although the influence here is of a mediated character and may by no means be reduced to processes in the non-bookish language being reflected in the bookish language.

The differences in the evolution of the bookish language compared with those of the spoken tongue arose by force of the fact its starting point was not the speech of the older generation, as is the case with the oral language, but the corpus of texts for reading, created at various times; this corpus functioned as the sum of the linguistic practices of many generations and conditioned the conservatism of bookish usage in comparison with oral. At the same time the correlation with such a broad and chronologically disparate body of texts made the hybrid language rather heterogeneous, in any case according to the standard of homogeneity that literary languages of the new type have made us expect. The bookman could to a greater or lesser extent adapt the usage he

\footnotetext{
Understandably, reinterpretation may change the status of the variants involved, gradually turning occasional deviations into stable features of usage. Thus, for example, F. Otten, analyzing the Stepennaia kniga (Otten 1973), demonstrates that inconsistency in forming the imperfect from verbs of the fourth class (with l-epenthenticum or without it) are met significantly more often in the last two parts of the chronicle than in the beginning. One may hypothesize that the occasional variants in ancient chronicle collections (on which see Khaburgaev 1991) are interpreted by the fourteenth-century author as precedents that justify a usage that he finds more convenient, with which he can create an imperfect from the familiar л-form without thinking. We find an eloquent example of the way in which the reinterpretation of a precedent was used by a chronicler in order to avoid difficulties in creating various forms in the Tsarstvennaia kniga [Royal Book] of the late sixteenth century (PSRL, XIII, 506). In the description of the siege of Kazan', the newest layer of the chronicle, we read: "И много розни въ городь сотвориша: овїи хотяху за неизможенїе бити челомъ государю нашему; инїи измьнннки воду начаша копати и не обрђтоша, но токмо малъ потокъ докопашася смраденъ, и до взятїя взимаху воду с нужею, от тое же воды бользнь бяше въ нихъ, пухли и умираху съ нее.” The chronicler evidently had difficulty creating the imperfect form from the verb пухнути, which he clearly could not derive from the written tradition. He therefore preferred using a combination of the л-form and the imperfect in the capacity of coordinated elements (пухли and умираху). This freedom was the result of reinterpreting the written tradition, in which this kind of word combination could sometimes be met. It was just this sort of reinterpretation and the use of the forms it produced that contributed to the evolution of the written tradition.
} 
had assimilated to his own spoken practices or could orient the text he was creating on more or less archaic layers of the corpus, whether or not he was following a particular archaizing or modernizing agenda. Because of this state of affairs, some texts in the hybrid register could radically differ from standard bookish ones while others could be very similar in many of their linguistic characteristics.

As we have suggested, the fundamental difference between standard and hybrid registers depended on their relation to the mechanism of orientation on models and the mechanism of retabulation. Understandably, the border between the two registers remained imprecise, especially in the earlier period when the distance between the bookish and non-bookish language had not yet become such that many markers of bookishness acquired unconditional status. Insofar as continuity in the bookish language was realized as a transformation of the habits of reading into the habits of writing, its concrete parameters depended not only on linguistic but also literary history. The immediate guide for a bookman and the source of his templates was not so much the whole corpus of literature that he had read as the texts of that "genre" to which the text he was creating belonged. Therefore chronicles were situated in the line of succession of chronicles, hymnographical works in the line of hymnographical works, and so on. ${ }^{8}$ And of course in literary history the mechanism of reconceptualization is also at work, so that chronicles may be seen not only as annalistic works but as narratives in the broader sense, so that they may serve as a model not only for other chronicles, but for any narrative (for example, saints lives, or in the seventeenth century, romances). This sort of branching out of textual continuity was conditioned by the course of the literary process, so that in this respect the history of the bookish language was connected in the most intimate way with the history of literature, and, in particular, with its social aspect.

In the course of centuries the conditions of literary activity significantly changed, and although the social composition, size, and occupations of that small portion of medieval society that one can see as analogue of the modern literary public (creators and consumers of books) have been insufficiently studied, primarily because of the lack of evidence,

On the notion of templates and their role in a person's reinterpretation of linguistic experience, see: Nichols and Timberlake 1991; Timberlake 1996. On the qualifications necessary to apply the notion of "genre" in the history of Eastern Slavic writing, see: Lenhoff 1984; Seeman 1987; Marti 1989. On the "generic" factor in the history of Slavic literary languages, see Tolstoi 1978; Alekseev 1987a, 44-5. 
these factors clearly did not remain unchanged from the eleventh through the seventeenth centuries (and equally so, say from the thirteenth though sixteenth). In sixteenth century Muscovy there could hardly have existed someone like the thirteenth-century Novgorodian sexton Timofei who copied church books, kept chronicles, and compiled treaties (see Gippius 1992). In the sixteenth century literary activity clearly became more differentiated, so that each of these activities was associated (even if not unambiguously) with a particular circle of people with more or less professional preparation (of course, not in the modern sense). Given such differentiation, potential authors' circle of reading also separates out, as well as the scope and character of their linguistic experience acquired in assimilating the particular corpus of texts.

This differentiation should have led to the consolidation of the various registers of the written language. Understandably, we are dealing here with a long term, gradual process that makes precise dating, and indeed any dating at all, fairly conditional. One may say definitely that in the sixteenth-seventeenth centuries a special type (register) of the bookish language came into being that manifested its writers' particular linguistic position and which formed its own tradition. A monk who was composing the canon of a newly glorified saint clearly felt himself in a different literary and linguistic tradition than a worker in the patriarchal chronicle scriptorium (like Isidor Skazkin, compiler of the Mazurinskii chronicle - see Koretskii 1968), and the latter did not feel at home in the language that a clerk preparing responses to petitions had assimilated. As a result of the consolidation of written traditions they could function as relatively autonomous systems so that it becomes possible to remake a text from one register into another. The revision of the Life of Mikhail Klopskii, carried out by Vasilii Tuchkov in Moscow in the first half of the sixteenth century, may serve as an example of this. We may surmise that Tuchkov felt that the hybrid language of the first draft was more fitting for a chronicle than for a saint's life so that he tried to rework the text to conform to the demands of the standard register (see Dmitriev 1958; Zhivov 1992a, 262-3). By the end of the seventeenth century the autonomy of the hybrid register was felt so strongly that it could be considered as a special "simple" tongue into which texts could be translated that previously existed only in standard Church Slavonic (I have in mind Firsov's 1683 translation of the Psalter - see below).

Moreover, the reconceptualization of the hybrid language as "simple" relates to the period that immediately preceded the Petrine linguistic reform and represents one of the reinterpretations of the entire medieval heritage that took place on the threshold of the new era. In the earlier period one could hardly speak of the special culturological (or symbolic) significance of 
the hybrid register or of its being associated with a particular value system. Although particular traditions of writing appeared and gradually crystallized within the bookish tradition there was no corresponding differentiation of cultural space. One cannot say, for example, that the standard register was associated with religious values and the hybrid with secular culture or that the standard register belonged to highbrow culture and hybrid to the lowbrow. The sphere of bookish culture continued to be concentrated around a single center, which was embodied (in terms of texts) in Holy Writ and liturgical books (cf. Edlichka 1976; Alekseev 1987a). In the hierarchical edifice of Eastern Slavic medieval literature these texts served as the absolute, ontological cornerstone, the ideal and model for the entire cultural space (cf. Picchio 1973; Alekseev and Likhachev 1987, 69).

This applies in the most direct way to texts in standard Church Slavonic, which were immediately connected to religious life, and for which the basic corpus of texts (Holy Writ and liturgy) served as the direct model ideological, literary, and linguistic. However, hybrid texts were not separated from this core of texts by any clearly recognized and formulated differences. As noted in regard to their language, these may significantly differ from the standard Church Slavonic and in the strength of these differences form their own separate tradition, i.e., they were not oriented on this central core directly but via the key monuments of some particular "genre." Nonetheless these differences were evidently perceived as acceptable departures, used out of weakness rather than design, a kind of poetic license. Thus the benchmark for the "correct" and hybrid written languages remained the texts of the main corpus, and hybrid texts were still considered part of Christian culture rather than some something standing apart. This is seen most clearly in the example of chronicles.

In his day I. P. Eremin wrote quite extensively about the significance of chronicles as a unique part of religious literature that depicts God's providence working itself out in human history (Eremin 1966, 64-71). Their main idea therefore remained religious - to show the achievements and sufferings of humankind (or a small part of it) on its path to salvation and to derive spiritual lessons from them. For this view of history the fundamental religious texts remained the central and most important source, apart from the question of how many times the chronicler cites the Bible or some other chronicle. At the same time, the interconnection of one chronicle with another was just as natural. They do not so much continue the record of events begun by their predecessors as document new stages revealing the divine plan for humanity. This view of chronicle writing may not only be reconstructed from 
the way historical events are presented in them but is also very explicitly expressed by the Eastern Slavic annalists themselves. ${ }^{9}$

It is understandable that if this religious understanding is characteristic of chronicle writing, it is no less central to other hybrid texts, for example, saints lives written in this register. Furthermore, this common understanding made possible the mutual interaction of various types of text, for example, using fragments from chronicles in hagiography or incorporating saints lives, patericons, and tales of miraculous icons into collections of chronicles, in whole or in part. United by a common religious understanding, these texts did not form precise generic groups and redistributed textual material in a relatively free fashion. Given this historical and literary background the borders between registers of the bookish language were not particularly precise, and in any case were not perceived as manifestations of cultural differentiation.

\section{The Reconceptualization of the Varieties of the Bookish Language}

The process of culturological reconceptualization of the varieties of the bookish language began within bookish culture and its starting impulses may be glimpsed in its own dynamic development rather than in external stimuli. The processes of functional reconceptualization of genetically heterogeneous elements discussed earlier was the result of the interaction of the bookish and non-bookish languages and may be seen as the accommodation of the bookish language to local conditions. From a certain point of view, however, such accommodation represents corruption (cf. the perception of colloquial Greek by Byzantine connoisseurs of classical culture or the Humanists' view of medieval Latin), and this idea, that is potentially present in the conception of any bookish language, only awaits the appropriate cultural conditions to become an active factor in its transformation. In Muscovite Rus' such conditions occurred in the late fourteenth century, when the unification of the Orthodox world became the common concern of Constantinople and the Slavic lands, and they put into motion the process that is traditionally called the "Second South Slavic influence," although a more fitting label should have been found long ago.

9 See, for example, the end of the Rogozhskii chronicle [...] (PSRL, XV, col. 185). 